\begin{tabular}{|l|l|l||}
\hline \multicolumn{2}{|c|}{ PublisherInfo } \\
\hline \hline PublisherName & $:$ & BioMed Central \\
\hline \hline PublisherLocation & $:$ & London \\
\hline \hline PublisherImprintName & $:$ & BioMed Central \\
\hline \hline
\end{tabular}

\title{
Gene transfer and gene analysis in normal T lymphocytes
}

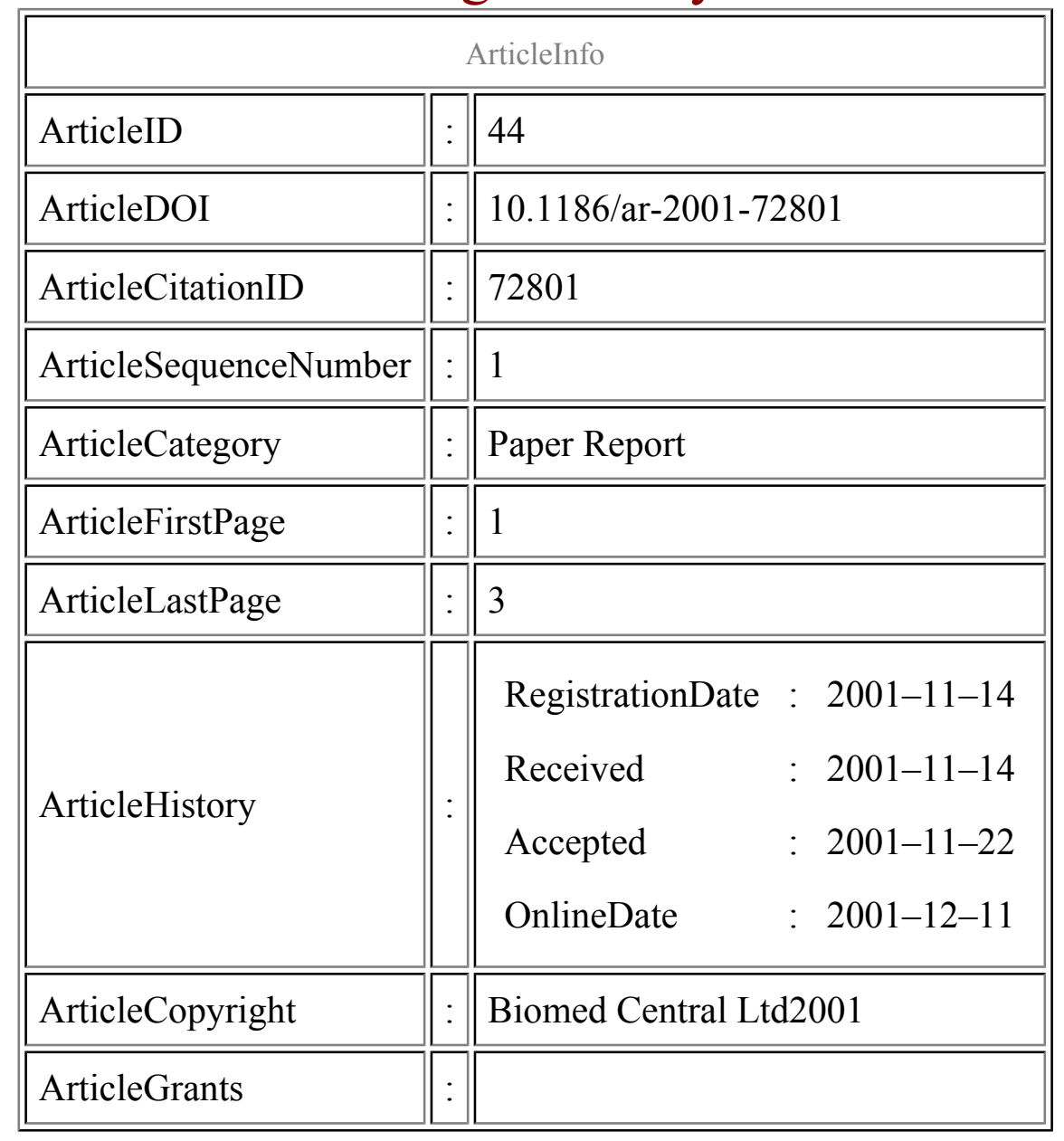




\begin{tabular}{|l|l|l|}
\hline ArticleContext & $:$ & 130753311 \\
\hline
\end{tabular}

Elvire Gouze, ${ }^{\text {Aff1 }}$

Aff1 Harvard Medical School, Boston, MA, USA

\section{Keywords}

Gene transfer, $\mathrm{T}$ lymphocytes, transfection

\section{Context}

The activation of $\mathrm{T}$ lymphocytes requires the correct combination of T-cell receptor (TCR)-mediated and costimulatory signals. Following the recognition of MHC-bound antigen by TCR, the interaction of CD28 with B7-1 and B7-2 molecules on antigen presenting cells is required to trigger IL-2 production which stimulates T-cell proliferation. TCR binding in the absence of CD28 costimulation can cause clonal deletion or T-cell anergy. The pathways that co-ordinate the signals between TCR and CD28 stimulation have not been elucidated. One impediment to the study of T-cell activation has been the inability to deliver efficiently exogenous DNAs to normal, unstimulated T cells. Much of the information on receptor-initiated intracellular signaling mechanisms has been gathered from transfection studies in tumor cell lines or from normal $\mathrm{T}$ lymphocytes previously activated in vitro. To facilitate the study of these signaling cascades, the authors have developed novel methods for transient transfection of nondividing, normal T cells.

\section{Significant findings}

To allow comparison of signaling pathways between immature and mature $\mathrm{T}$ cells, the authors initially optimized conditions for electroporation-mediated transfection of murine $\mathrm{CD} 4^{+} \mathrm{CD} 8^{+}$doublepositive (DP) thymocytes and the Jurkat T-cell line. Using green fluorescent protein (GFP) as a marker gene, several parameters were evaluated including the voltage, pulse number and length, expression vectors and quantity of DNA. The authors optimized conditions for DNA uptake and expression. When these conditions were applied to transfection of nondividing murine and normal human $\mathrm{T}$ cells it was found that a significant proportion of the cells expressed the transgene and remained viable after 24 hours. To test the ability of the method to deliver genes encoding intracellular kinases to $\mathrm{T}$ cells, plasmid constructs of constitutively active mitogen activated kinase kinase-1 fused to GFP or a FLAG tag were delivered to DP thymocytes and found to induce $B c l-2$ expression. Using a reporter plasmid encoding 
luciferase under control of NF-?B response elements it was shown that TCR and CD28 mediated signals were linked in distinct manners in different T-cell populations.

\section{Comments}

It is believed that $\mathrm{T}$ lymphocytes have a central role in both etiological and pathological processes of rheumatoid arthritis. However, the mechanisms by which they exert their pathological effects are not totally elucidated. In several models (e.g. collagen induced arthritis) it has been shown that blocking the CD28 costimulatory signaling pathways can prevent or treat the disease. The ability to deliver exogenous DNAs to normal T lymphocytes should enable a better understanding of the mechanisms of T-cell activation and possibly provide novel therapeutic targets for the treatment of arthritis.

Nevertheless, viability still presents a problem when electroporation-mediated gene delivery is used. While the publication of new technologies may be very valuable, methodological details provided in this particular study are on the brief side for a "methods" paper.

\section{Methods}

Transient transfection, electroporation, flow cytometry, plasmid DNA

\section{Additional information}

\section{References}

1. Bell MP, Huntoon CJ, Graham D, McKean DJ: The analysis of costimulatory receptor signaling cascades in normal T lymphocytes using in vitrogene transfer and reporter gene analysis. Nat Med . 2001, 7: 1155-1158.

This PDF file was created after publication. 